\title{
What is professional?
}

Shaun Sellars continues his series on ethical dilemmas in dentistry which appears in every

second issue of the $B D J$.

Towards the end of last year the GDC, in conjunction with Cardiff University, conducted a survey into professionalism in dentistry. The study targeted the general public as well as those within dentistry and gathered information on what each group considered to be the boundaries of professional behaviour. As with most things our regulator does, reactions were mixed with a vocal section of the profession voicing their concern that the results of the survey may be used against them in the future. These concerns are, in some way, justified, but that's because of how the concept of professionalism is constructed.

When considering professionalism, it's worthwhile stepping back and looking at a couple of basic concepts of how we perceive the world and how our values fit in with it. If we take a relativistic viewpoint, we're saying that there is no ultimate right or wrong. Any disagreements in moral values are acceptable, as each view has a degree of validity. This is a tempting stance to take in our ever more liberal outside world, but in the sphere of dentistry, it is unrealistic. In dentistry, we take a much more objective view of right and wrong actions.

We already know that there are certain things that we should not be doing, whether that be related to certain forms of treatment or regarding our behaviour outside of work. It's the latter that forms part of our professional status. As dentistry advances, so does what we consider to be appropriate treatment. What was deemed to be acceptable clinically in the 1970s, for example, may not be

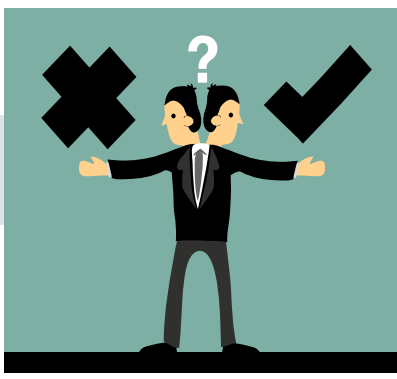

acceptable in the twenty-first century. In much the same way professional standards have changed. What has not changed is the fact that being professionals we have a number of ethical and moral obligations.

In the rest of the world, what's viewed as right or wrong is shaped by society. This means that over time, the moral stance of society will change. The same goes for dentistry. What we understand by the term will change over time. To fully appreciate what society (and dentistry) thinks is appropriate conduct, research needs to be carried out.

It could be argued that the GDC are not the right people to conduct this research. There's a potential conflict of interest and many dentists refused to complete the survey because of this. But the real risk is to try and guess at what we consider acceptable and then have rulings based on that. We all live in our bubble in which we may believe our values and judgements to be sacrosanct. Still, if we're going to have a regulator that genuinely operates on a 'right touch' basis, then we need to understand what society as a whole, and not ourselves as individuals, deems to be appropriate. The only way to do this is to collect the information from dental professionals and the wider community. And yes, we will be judged by this. But that's because we should be.

\section{OMFS and ENT surgeons issue new COVID-19 PPE guidance}

New personal and protective equipment (PPE) guidance from the British Association of Oral and Maxillofacial Surgeons (BAOMS) and ENT UK advises surgeons on how to treat patients with emergency oropharyngeal and nasopharyngeal conditions.

BAOMS Chair Patrick Magennis explained: 'Some patients with these conditions, but whose COVID-19 status is unknown, might require examination or treatment including biopsy, nasoendoscopy, extraction/SR of teeth or intra-oral biopsies'.

ENT UK President Nirmal Kumar said: 'This is a welcome and timely acknowledgement from Public Health England (PHE) that all clinicians working in close proximity to the upper airway and face will incur some form of contact with aerosols (Aerosol Generating Procedures/AGPs).

'PHE is rightly assuming that there are many asymptomatic individuals now in the community, which means that wearing full PPE is essential for any examination or procedures in all patients.'

The new guidance advises that for non-oral conditions such as head and neck skin lesions, where examination and treatment does not involve oral/nasal examination, normal COVID PPE guidance applies.

For full information about the new guidance go to BAOMS: www. baoms.org.uk; ENT UK: www.entuk.org and BAOS: www.baos.org.uk.
BDA UPDATE

British Dental Association (the 'Company') (Registered in England and Wales with company number 14161)

Annual General Meeting

NOTICE IS HEREBY GIVEN that the Annual General Meeting of the British Dental Association scheduled to be held at 3.45 pm on Thursday 30 April 2020 at the British Dental Association, 64 Wimpole Street, London W1G 8YS has been postponed until further notice.

As such, the arrangements agreed at the AGM of 2 May 2019 remain extant.

A notice will be posted in the British Dental Journal regarding a future date when circumstances make such a meeting possible.

DATED April 2020

BY ORDER OF THE PRINCIPAL EXECUTIVE COMMITTEE

Registered office:

64 Wimpole Street

London W1G 8YS 